\title{
Phase I study of oral S-1 and concurrent radiotherapy in patients with head and neck cancer
}

\author{
Kensei NAKATA ${ }^{1, *}$, Koh-ichi SAKATA ${ }^{1}$, Masanori SOMEYA ${ }^{1}$, Katsutoshi MIURA ${ }^{1}$, \\ Junichi HAYASHI ${ }^{1}$, Masakazu HORI ${ }^{1}$, Masaru TAKAGI ${ }^{1}$, Tetsuo HIMI ${ }^{2}$, Atsushi KONDO² \\ and Masato HAREYAMA ${ }^{1}$
}

\begin{abstract}
${ }^{1}$ Department of Radiology, Sapporo Medical University, S-1, W-16, Chuo-ku, Sapporo, 060-8543, Japan
${ }^{2}$ Department of Otolaryngology, Sapporo Medical University, S-1, W-16, Chuo-ku, Sapporo, 060-8543, Japan

*Corresponding author. Department of Radiology, Sapporo Medical University. S-1, W-16, Chuo-ku, Sapporo, 060-8543,

Japan. Tel: + 81-11-611-2111 ext. 3535; Fax: + 81-11-613-9920; Email: kensei@ sapmed.ac.jp
\end{abstract}

(Received 9 April 2012; revised 5 December 2012; accepted 5 December 2012)

\begin{abstract}
This study investigated the maximum tolerated dose (MTD) of S-1 with concurrent radiotherapy in patients with head and neck cancer, based on the frequency of dose-limiting toxicities (DLT). S-1 was administered orally at escalating doses from $40 \mathrm{mg} / \mathrm{m}^{2}$ b.i.d. on the days of delivering radiotherapy, which was given at a total dose of 64-70 Gy in 32-35 fractions over 6-7 weeks. A total of 12 patients (3 patients at $40 \mathrm{mg} / \mathrm{m}^{2}, 6$ patients at $60 \mathrm{mg} / \mathrm{m}^{2}$, and 3 patients at $80 \mathrm{mg} / \mathrm{m}^{2}$ ) were enrolled in this trial. At the dose of $80 \mathrm{mg} / \mathrm{m}^{2}$, two of the three patients developed DLT (Grade 3 anorexia and rhabdomyolysis) due to S-1, so the MTD was determined to be $80 \mathrm{mg} / \mathrm{m}^{2}$. Among the 12 enrolled patients, $9(75 \%)$ showed a complete response and 3 $(25 \%)$ showed a partial response. The overall response rate was $100 \%$. The recommended dose of S-1 with concurrent radiotherapy is $60 \mathrm{mg} / \mathrm{m}^{2}$.
\end{abstract}

Keywords: head and neck cancer; chemoradiotherapy; S-1; Phase I study

\section{INTRODUCTION}

Platinum-based chemotherapy has been the chief regimen used in studies of concurrent chemoradiotherapy (CCRT) [1]. However, platinum-based regimens cannot be administered to patients with features such as advanced age, renal dysfunction, or refusal of hospitalization. Therefore, chemotherapy that can be delivered to such patients during radiotherapy is required.

$\mathrm{S}-1$ is a novel oral drug, which is a combination of tegafur, 5-chloro-2,4-dihydroxypyridine (gimeracil), and potassium oxonate (oteracil) at a 1:0.4:1 molar concentration ratio [2]. Tegafur is hydroxylated and converted to 5-FU by hepatic microsomal enzymes. After intravenous injection, more than $85 \%$ of 5 -FU is rapidly catabolized by the enzyme dihydropyrimidine dehydrogenase (DPD) [3]. Gimeracil is a competitive inhibitor of DPD that prevents the rapid degradation of 5-FU, and acts to maintain effective 5-FU levels in the plasma and tumor tissue. It is 180 times more potent than uracil, the DPD inhibitor found in uracil-tegafur (UFT), so an effective concentration of 5-FU is maintained in both the plasma and tumor tissue after S-1 administration [4]. We previously found that gimeracil also has a radiosensitizing effect by inhibiting the repair of double-stranded DNA breaks [5]. Oteracil is a competitive inhibitor of orotate phosphoribosyltransferase (OPRT), which inhibits phosphorylation of 5-FU in the gastrointestinal tract and thus reduces serious gastrointestinal toxicity associated with 5-FU therapy [6].

The antitumor effect of S-1 has already been demonstrated in patients with a variety of solid tumors, including advanced gastric cancer [7], colorectal cancer [8], non-small-cell lung cancer [9], and head and neck cancer [10]. Thus, S-1 has shown promising antitumor activity against head and neck cancer, and is much more convenient than continuous intravenous 5-FU infusion as it is administered orally. Radiotherapy could be combined with S-1 therapy in patients for whom platinum-based chemotherapy is not applicable. Therefore, we conducted a Phase I trial to determine the maximum tolerated dose of S-1 with concurrent radiotherapy in patients with head and neck cancer, based on the frequency of dose-limiting toxicities (DLT). 


\section{MATERIALS AND METHODS}

\section{Eligibility}

Patients with histopathologically proven squamous cell carcinoma of the head and neck were eligible for this study. They were required to be at least 20 years old, to have an Eastern Cooperative Oncology Group performance status of 2 or less, and to have adequate organ function (leukocytes $\geq 3500 / \mathrm{mm}^{3}$, platelets $\geq 100000 / \mathrm{mm}^{3}$, hemoglobin $\geq 9.0 \mathrm{~g} / \mathrm{dl}$, normal serum creatinine and blood urea nitrogen, serum glutamic oxaloacetic transaminase $(\mathrm{GOT}) \leq 100 \mathrm{U} / \mathrm{l}$, serum glutaminic pyruvic transaminase $(\mathrm{GPT}) \leq 100 \mathrm{U} / \mathrm{l}$, and serum albumin $\geq 3.0 \mathrm{~g} / \mathrm{dl}$ ). Patients were excluded if they had received prior systemic therapy or radiotherapy, had another active malignancy, active infection, active gastric/duodenal ulcer, severe concurrent disease, or mental disorder.

This study was performed according to the guidelines of the Declaration of Helsinki (as amended in Edinburgh, Scotland in October 2000) and its protocol was approved by the Institutional Review Board of Sapporo Medical University School of Medicine. All patients gave written informed consent before being enrolled in this study.

\section{Treatment}

Fig. 1 shows the treatment schedule. Radiotherapy was initiated on Day 1 of the study using $4 \mathrm{MV}$ photons. A fractional daily dose of 2.0 Gy (5 days/week) at the isocenter was given till a total dose of 64-70 Gy had been administered. Treatment planning was performed with a CT simulator (Asteion; Toshiba Medical Systems, Tokyo, Japan) for all patients, and the dose distribution was calculated with a 3D treatment planning system (Xio; CMS Japan KK, Tokyo, Japan).

S-1 (Taiho Pharmaceutical Co., Tokyo, Japan) was administered orally twice a day after meals every day, except on the weekends and holidays when radiotherapy was not performed. Each capsule of S-1 contained 20 or $25 \mathrm{mg}$ of tegafur, and individual doses were rounded down to the nearest amount less than the dose calculated according to the body surface area, using the two available formulations.

The initial dose of S-1 was $40 \mathrm{mg} / \mathrm{m}^{2} /$ day (Level 1), and the dose was escalated to $60 \mathrm{mg} / \mathrm{m}^{2} /$ day (Level 2) and 80 $\mathrm{mg} / \mathrm{m}^{2} /$ day (Level 3). The initial dose level of S-1 (40 mg/ $\mathrm{m}^{2} /$ day) was selected because it was deemed to be safe based on our prior experience of S-1 (50 mg/body/day) chemoradiotherapy (CRT).

Evaluations during CRT included a weekly history, physical examination, hematology and biochemistry, and assessment of toxicity. DLT was defined as Grade 3 or 4 nonhematologic toxicity (excluding Grade 3 radiation mucositis and dermatitis), Grade 4 hematologic toxicity occurring during treatment or within two weeks after completing treatment, or requirement for suspension of either S-1 or radiation therapy for seven days or more. If mucositis became severe, we managed it with appropriate analgesics and mucosal protective agents in order to alleviate the symptoms. If none of the three patients experienced any DLTs at a given dose level, the dose of S-1 was escalated for the next cohort of three patients. If one of the initial three patients experienced a DLT, three more patients were added at that dose level. Dose escalation continued if DLTs were only observed in one or two out of six patients. If three or more patients experienced DLTs at a dose level, the previous dose level was defined as the maximum tolerated dose (MTD). Thus, if two or three of the initial three patients experienced DLTs, the starting dose level would be the MTD.

\section{RESULT}

\section{Patient characteristics}

A total of 12 patients were enrolled in this study between April 2008 and December 2009. The characteristics of the eligible patients are outlined in Table 1: Nine of the patients were men and three were women, with a median age of 71 years. None of the patients had received prior chemotherapy or radiation therapy.

\section{Toxicity}

All treated patients $(n=12)$ were assessed for toxicities. The toxicities observed during treatment or within two weeks of completing treatment are listed in Table 2. Three patients were treated with $\mathrm{S}-1$ at dose Level $1\left(40 \mathrm{mg} / \mathrm{m}^{2} /\right.$ day) and six patients at dose Level $2\left(60 \mathrm{mg} / \mathrm{m}^{2} /\right.$ day $)$. Of the latter, one experienced rapid-onset Grade 1 thrombocytopenia with a systemic maculopapular rash. After the

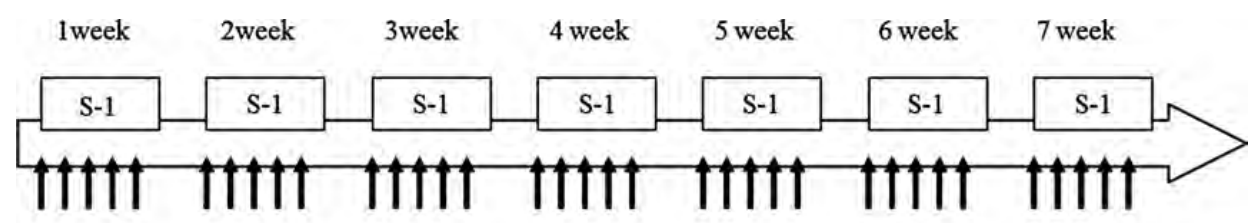

$2.0 \mathrm{~Gy} /$ fraction total dose $64-70 \mathrm{~Gy} / 6-7$ weeks

Fig. 1. The treatment schedule: S-1 was administered by the amount at each level on the day with the radiation therapy. Radiation therapy was delivered as a total dose of 64-70 Gy in 32-35 fractions over 6-7 weeks. 
Table 1. Background of the patients

\begin{tabular}{|c|c|c|c|c|c|c|c|c|}
\hline Case & Age & Sex & Tumor site & Classified TNM & S-1 & RT & Eq. Sqm & Efficacy \\
\hline \multicolumn{9}{|c|}{ Level 1} \\
\hline 1 & 59 & M & Supra glottic & T1N0M0 & $40(60)$ & 70 & 9.2 & $\mathrm{CR}$ \\
\hline 2 & 62 & $\mathrm{M}$ & Supra glottic & T2N0M0 & $40(60)$ & 68 & 9.2 & $\mathrm{CR}$ \\
\hline 3 & 55 & $\mathrm{~F}$ & Oropharynx & T2N1M0 & $40(50)$ & 70 & 10.5 & $\mathrm{CR}$ \\
\hline \multicolumn{9}{|c|}{ Level 2} \\
\hline $4^{*}$ & 79 & M & Neck L/N & TxN3M0 & $60(80)$ & 70 & 10.0 & PR \\
\hline 5 & 64 & $\mathrm{M}$ & Glottic & T2NOM0 & $60(90)$ & 70 & 6.0 & $\mathrm{CR}$ \\
\hline 6 & 70 & $\mathrm{M}$ & Hypopharynx & $\mathrm{T} 2 \mathrm{~N} 1 \mathrm{M} 0$ & $60(80)$ & 70 & 13.5 & $\mathrm{CR}$ \\
\hline $7 *$ & 79 & $\mathrm{~F}$ & Buccal membrane & T1N0M0 & $60(80)$ & 66 & 8.3 & $\mathrm{CR}$ \\
\hline 8 & 83 & $\mathrm{M}$ & Supra glottic & T2N0M0 & $60(80)$ & 66 & 8.3 & $\mathrm{CR}$ \\
\hline 9 & 76 & $\mathrm{M}$ & Subglottic & T2N0M0 & $60(90)$ & 66 & 10.6 & $\mathrm{CR}$ \\
\hline \multicolumn{9}{|c|}{ Level 3} \\
\hline 10 & 72 & $\mathrm{~F}$ & External auditory canal & T4N0M0 & $80(100)$ & 64 & 7.7 & PR \\
\hline $11^{*}$ & 69 & M & Supra glottic & T2N0M0 & $80(120)$ & 70 & 9.2 & PR \\
\hline $12 *$ & 77 & M & Hypopharynx & $\mathrm{T} 2 \mathrm{~N} 2 \mathrm{bM} 0$ & 80 (120) & 66 & 16.0 & $\mathrm{CR}$ \\
\hline
\end{tabular}

$\mathrm{S}-1=$ dose of daily $\mathrm{S}-1 \mathrm{mg} / \mathrm{m}^{2}$ (mg/body), RT = total radiation dose $(\mathrm{Gy})$, Eq. Sqm = equivalent square meter of radiation field length $(\mathrm{cm}), *$ patient who experienced dose-limiting toxicity.

dose of S-1 was reduced, there was no improvement of these symptoms, so S-1 was stopped. In addition, one patient experienced Grade 3 mucositis at a radiation dose of approximately $20 \mathrm{~Gy}$.

Of the initial three patients treated with $\mathrm{S}-1$ at dose Level $3\left(80 \mathrm{mg} / \mathrm{m}^{2} /\right.$ day $)$, one experienced Grade 4 anorexia and one experienced an increase of serum CPK due to rhabdomyolysis caused by $\mathrm{S}-1$.

After treatment was stopped, these adverse events all improved. There were no Grade 2 or higher events in any of the patients.

\section{Response and survival}

At the initial evaluation immediately after CRT, a complete response was seen in $9(75 \%)$ of all 12 patients and a partial response was seen in $3(25 \%)$. Stable disease or progressive disease was not encountered. During a median follow-up period of 35 months (range, 3-45 months), distant metastases developed in 1 patient and local failure occurred in 1 patient.

\section{DISCUSSION}

The main goal of this study was to find the dose of S-1 that could be safely combined with radiotherapy in patients with head and neck cancer. Radiation alone is the standard treatment for T1 or T2 glottic cancer and T1N0M0 nasopharyngeal cancer [11]. However, treatment with radiation alone does not achieve satisfactory results in patients with other head and neck tumors that are T1-2 and N0 [12]. Concurrent chemoradiotherapy might be one possibility for improving the outcomes for these patients [13], so we included head and neck cancer patients with T1-2N0M0 tumors other than cancer of the glottis or nasopharynx in this study.

Because severe mucositis is one of the major complications of radiotherapy for head and neck cancer, it is often difficult to determine whether CRT or RT has caused it, so Grade 3 mucositis was excluded from DLT assessment in this study. Instead, we defined DLT as suspension of treatment for more than 7 days, so that it included severe mucositis which prevented patients from taking $\mathrm{S}-1$. We think that oral administration of $\mathrm{S}-1$ is important, because its main benefit is that we can treat patients on an ambulatory basis.

In general, the intensity of the side effects depends on the size of the radiation field. In this study, the average equivalent square meter (Eq.Sqm) field length was $9.9 \mathrm{~cm}$ (range, 6.0-16.0 cm). At dose Level 3, the Eq.Sqm of the patient with a DLT was $16 \mathrm{~cm}$. This patient developed Grade 3 mucositis that might have been due to a large radiation field. However, the reason for discontinuing S-1 was the increase of serum CPK. In patients with early head and neck cancer, the planning target volume is localized to the primary tumor, so the radiation field is smaller than for that of advanced head and neck cancer. If the average radiation 
Table 2. Toxicities

\begin{tabular}{|c|c|c|c|c|c|c|}
\hline & \multicolumn{5}{|c|}{$\begin{array}{l}\text { NCI-CTC } \\
\text { Grade }\end{array}$} & \multirow[t]{2}{*}{$\geqq$ Grade 3} \\
\hline & $\mathbf{0}$ & $\mathbf{1}$ & 2 & 3 & 4 & \\
\hline \multicolumn{7}{|c|}{ Level 1: $n=3\left(\mathrm{~S}-140 \mathrm{mg} / \mathrm{m}^{2}\right)$} \\
\hline Leukopenia & 2 & & 1 & & & \\
\hline Hemoglobinpenia & & 3 & & & & \\
\hline Thrombocytopenia & 3 & & & & & \\
\hline Dermatitis & & 1 & 1 & 1 & & $33 \%$ \\
\hline Mucositis & & 1 & 2 & & & \\
\hline Dysphagia & & & 3 & & & \\
\hline Diarrhea & 3 & & & & & \\
\hline \multicolumn{7}{|c|}{ Level 2: $n=6\left(\mathrm{~S}-160 \mathrm{mg} / \mathrm{m}^{2}\right)$} \\
\hline Leukopenia & 2 & 3 & 1 & & & \\
\hline Hemoglobinpenia & 1 & 4 & 1 & & & \\
\hline Thrombocytopenia & 4 & 2 & & & & \\
\hline Dermatitis & & & 1 & 5 & & $83 \%$ \\
\hline Mucositis & 1 & 1 & 3 & 1 & & $17 \%$ \\
\hline Dysphagia & & 3 & 2 & 1 & & $17 \%$ \\
\hline Diarrhea & 6 & & & & & \\
\hline \multicolumn{7}{|c|}{ Level 3: $n=3\left(\mathrm{~S}-180 \mathrm{mg} / \mathrm{m}^{2}\right)$} \\
\hline Leukopenia & 1 & 2 & & & & \\
\hline Hemoglobinpenia & 1 & 2 & & & & \\
\hline Thrombocytopenia & 3 & & & & & \\
\hline Dermatitis & & & 3 & & & \\
\hline Mucositis & 1 & & 1 & 1 & & $33 \%$ \\
\hline Dysphagia & 2 & & & 1 & & $33 \%$ \\
\hline Diarrhea & 2 & & 1 & & & \\
\hline
\end{tabular}

field was smaller than that used in this study, the MTD may be higher than our result. However, CRT is generally not indicated for early head and neck cancer, which is usually treated with small-field radiotherapy.

The rationale for CCRT is that chemotherapy agents may act as radiation sensitizers in addition to contributing their own antitumor effect [14]. In this study, we set up the administration schedule for S-1 expecting that gimeracil and 5-FU would act as sensitizers for radiotherapy. Therefore, we considered that the administration of S-1 on each day of radiotherapy was essential and we used the following schedule: S-1 was administered every day except on hospital holidays when radiotherapy was not delivered.

Chemoradiation schedules with S-1 that have previously been reported all included some weeks of planned S-1 suspension during radiotherapy. Tsuji et al. reported the results of an S-1 dose escalation study with 2 weeks of S-1 administration followed by 2 weeks off $\mathrm{S}-1$, and then 2 more weeks of S-1 administration during radiotherapy (total dose: $60 \mathrm{~Gy}$ ). They reported that the recommended dose (RD) of S-1 was $80 \mathrm{mg} / \mathrm{body} /$ day with their schedule [15]. Sato et al. reported that the RD of S-1 was $65 \mathrm{mg} / \mathrm{m}^{2} /$ day when radiation was given to a total dose of $60 \mathrm{~Gy}$ and S-1 was administered every day for 2 weeks and then was suspended for 1 week [16]. In addition, Tsukuda et al. reported that the RD of S-1 was $80-100 \mathrm{mg} /$ body/day when radiation was given to a total dose of 60-70.2 Gy, and S-1 was administered every day for 2 weeks and was then suspended for 1 week [17]. Furthermore, Harada et al. reported the results of an S-1 dose escalation study that had almost the same schedule as our study. They stated that the RD of $\mathrm{S}-1$ to be $65 \mathrm{mg} / \mathrm{m}^{2} /$ day with administration on 5 days per week [18]. The difference from our study is that their total radiation dose was only $40 \mathrm{~Gy}$ because they were giving preoperative concurrent chemoradiotherapy. There have been other reports on Phase III trials of radiotherapy with S-1 [19-23] or the combination of S-1 and cisplatin/nedaplatin [24-26] for head and neck cancer. These studies have demonstrated that S-1 and concurrent radical radiotherapy is safe and well tolerated by patients with complications and is a patient-friendly treatment. In the CRT schedules of all these studies, some weeks of planned interruption of S-1 administration occurred during radiation therapy. To the best of our knowledge, therefore, this is the first Phase I trial of concurrent $\mathrm{S}-1$ and radical radiotherapy for head and neck cancer, in which S-1 was administered continuously during the period of radiotherapy.

In this study, oral S-1 and concurrent radiotherapy were well tolerated and feasible. The MTD was reached at dose Level $3\left(80 \mathrm{mg} / \mathrm{m}^{2} /\right.$ day $)$, so we concluded that the RD of S-1 with concurrent radiotherapy is $60 \mathrm{mg} / \mathrm{m}^{2} /$ day. Compliance with the regimen was satisfactory and all patients completed their planned radiotherapy. Evaluation of efficacy was not the primary objective of this small Phase I study. To evaluate the long-term outcomes and potential late complications of our regimen, we will continue to accumulate patients and follow them over the long term. We are currently conducting a Phase II study of S-1 and concurrent radical radiotherapy in patients who are not suitable for platinum-based chemoradiotherapy.

\section{CONCLUSION}

In conclusion, this study showed that S-1 and concurrent radical radiotherapy is feasible and well tolerated in patients with head and neck cancer. The RD of S-1 with concurrent radiotherapy was determined to be $60 \mathrm{mg} / \mathrm{m}^{2} /$ body on every day of radiation delivery. This combination therapy may be an attractive alternative to conventional CRT using infused 5-FU for head and neck cancer because of its convenience and feasibility. 


\section{ACKNOWLEDGEMENTS}

This article was presented at the ASTRO 52nd annual meeting held in October-November 2010.

\section{FUNDING}

This work was supported by Sapporo Medical University.

\section{REFERENCES}

1. Pignon JP, le Maître A, Maillard E et al. Meta-analysis of hemotherapy in head and neck cancer (MACH-NC): an update on 93 randomised trials and 17,346 patients. Radiother Oncol 2009;92:4-14.

2. Shirasaka T, Shimamoto Y, Ohshima H et al. Development of a novel form of an oral 5-fluorouracil derivative (S-1) directed to the potentiation of the tumor selective cytotoxicity of 5-fluorouracil by two biochemical modulators. Anticancer Drugs 1996;7:548-57.

3. Heggie GD, Sommandossi JP, Cross DS et al. Clinical pharmacokinetics of 5-fluorouracil and its metabolites in plasma, urine, and bile. Cancer Res 1987;47:2203-6.

4. Tatumi K, Fukushima M, Shirasaka T et al. Inhibitory effects of pyrimidine, barbituric acid and pyridine derivatives on 5fluorouracil degradation in rat liver extracts. Jpn J Cancer Res 1987;78:748-55.

5. Takagi M, Sakata K, Someya M et al. Gimeracil sensitizes cells to radiation via inhibition of homologous recombination. Radiother Oncol 2010;96:259-66.

6. Shirasaka T, Shimamoto Y, Fukushima M. Inhibition by oxonic acid of gastrointestinal toxicity of 5-fluorouracil without loss of its antitumor activity in rats. Cancer Res 1993;53:4004-9.

7. Sakata Y, Ohtsu A, Horikoshi N et al. Late phase II study of novel oral fluoropyrimidine anticancer drug S-1 (1 M tegafur-0.4 M gimestat-1 M otastat potassium) in advanced gastric cancer patients. Eur J Cancer 1998;34:1715-20.

8. Ohtsu A, Baba H, Sakata Y et al. Phase II study of S-1, a novel oral fluorophyrimidine derivative, in patients with metastatic colorectal carcinoma. S-1 Cooperative Colorectal Carcinoma Study Group. Br J Cancer 2000;83:141-5.

9. Kawahara M, Furuse K, Segawa Y et al. Phase II study of $\mathrm{S}-1$, a novel oral fluorouracil, in advanced non-small-cell lung cancer. Br J Cancer 2001;85:939-43.

10. Inuyama $\mathrm{Y}$, Kida $\mathrm{A}$, Tsukukda $\mathrm{M}$ et al. Late phase II study of S-1 in patients with advanced head and neck cancer. Gan To Kagaku Ryoho 2001;28:1381-90.

11. National Comprehensive Cancer Network Guidelines Head and Neck Cancers Version 1.2012. http://www.ncen. org/professionals/physician_gls/pdf/head-and-neck.pdf (10 September 2012, date last accessed).

12. Leonard L, Gunderson Joel E et al. Clinical Radiation Oncology. 2nd edn. Philadelphia, Pennsylvania: Churchill Livingstone, 2006, 639-754.
13. Goshi N, Mamoru T, Yasukazu M et al. Efficacy of concurrent chemoradiotherapy for $\mathrm{T} 1$ and $\mathrm{T} 2$ laryngeal squamous cell carcinoma regarding organ preservation. Anticancer Res 2009;29:661-6.

14. Douple EB, Richmond RC, O'Hara JA et al. Carboplatin as a potentiator of radiation therapy. Cancer Treat Rev 1985;12 (Suppl A): 111-24.

15. Tsuji H, Nagata M, lnoue $\mathrm{T}$ et al. Clinical Phase I trial of concurrent chemo-radiotherapy with S-1 for T2N0 glottic carcinoma. Jpn J Cancer Chemother 2006;33 Suppl 1:163-6.

16. Sato M, Harada K. Phase I study of concurrent radiotherapy with S-1 for oral squamous cell carcinoma. Jpn J Cancer Chemother 2006;33 (Suppl 1):179-83.

17. Tsukuda M, Ishitoya J, Mikami Y et al. Analysis of feasibility and toxicity of concurrent chemoradiotherapy with S-1 for locally advanced squamous cell carcinoma of the head and neck in elderly cases and/or cases with comorbidity. Cancer Chemo Pharm 2009;64:945-52.

18. Harada H, Omura K. Preoperative concurrent chemotherapy with S-1 and radiotherapy for locally advanced squamous cell carcinoma of the oral cavity: phase I trial. J Exp Clin Cancer Res 2010;29:33.

19. Nakashima T, Toh S, Shiratsuchi H et al. Laryngeal preservation for hypopharyngeal cancer by radiotherapy with S-1 and vitamin A (TAR therapy). Gan To Kagaku Ryoho 2012;39:759-63.

20. Ohnishi K, Shioyama Y, Nakamura K et al. Concurrent chemoradiotherapy with S-1 as first-line treatment for patients with oropharyngeal cancer. J Radiat Res 2011;52:47-53.

21. Nonoshita T, Shioyama Y, Nakamura K et al. Concurrent chemoradiotherapy with $\mathrm{S}-1$ for T2N0 glottic squamous cell carcinoma. J Radiat Res 2010;51:481-4.

22. Nakayama M, Hayakawa K, Okamoto M et al. Phase I/II trial of concurrent use of S-1 and radiation therapy for T2 glottic cancer. Jpn J Clin Oncol 2010;40:921-6.

23. Tsukuda M, Ishitoya J, Mikami Y et al. Analysis of feasibility and toxicity of concurrent chemoradiotherapy with S-1 for locally advanced squamous cell carcinoma of the head and neck in elderly cases and/or cases with comorbidity. Cancer Chemother Pharmacol 2009;64:945-52.

24. Tahara M, Minami H, Kawashima M et al. Phase I trial of chemoradiotherapy with the combination of S-1 plus cisplatin for patients with unresectable locally advanced squamous cell carcinoma of the head and neck. Cancer Sci 2011;102:419-24.

25. Ohashi T, Ohnishi M, Tanahashi $\mathrm{S}$ et al. Efficacy and toxicity of concurrent chemoradiotherapy with nedaplatin and S-1 for head and neck cancer. Jpn J Clin Oncol 2011;41:348-52.

26. Nakamura K, Tahara M, Kiyota $\mathrm{N}$ et al. Phase II trial of concurrent chemoradiotherapy with $\mathrm{S}-1$ plus cisplatin in patients with unresectable locally advanced squamous cell carcinoma of the head and neck: Japan Clinical Oncology Group Study (JCOG0706). Jpn J Clin Oncol 2009;39:460-3. 